\title{
In vitro Elucidation of Antiproliferative and Apoptotic Effects of Thymol against Prostate Cancer LNCaP Cells
}

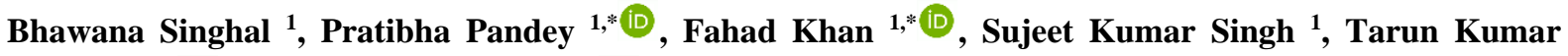 \\ Upadhyay $^{2(\mathbb{D})}$, Vijay Jagdish Upadhye ${ }^{2 \mathbb{D}}$, Mohammad Mustufa Khan ${ }^{3}$ \\ 1 Department of Biotechnology, Noida Institute of Engineering \& Technology, 19, Knowledge Park-II, Institutional Area, \\ Greater Noida, 201306, India; bhawanasinghal171@gmail.com (B.S.), shukla.pratibha1985@gmail.com (P.P.), \\ fahadintegralian@gmail.com (F.K.), sujeetsinghbiotech2007@gmail.com (S.K.S.); \\ 2 Parul Institute of Applied Sciences \& Centre of Research For Development, Parul University, Vadodara, Gujrat, India- \\ 391760; tarun_bioinfo@yahoo.co.in (T.K.U.),dr.vijaysemilo@gmail.com (V.J.U.); \\ 3 Department of Basic Medical Sciences, Integral Institute of Allied Health Sciences \& Research, Integral University, \\ Luckow, 226026; mustufakhan01084@gmail.com (M.M.K.); \\ * Correspondence: fahadintegralian@gmail.com (F.K.), shukla.pratibha1985@gmail.com (P.P.);
}

Scopus Author ID 57201049984

Received: 12.03.2021; Revised: 12.04.2021; Accepted: 15.04.2021; Published: 26.04.2021

\begin{abstract}
Recent research suggested the role of plant-derived bioactive compounds as potent anticancer agents. Thymol, a monoterpene phenol, possesses numerous pharmacological properties such as antioxidant, anti-inflammatory, and antitumor effects. However, the inhibitory potential of thymol on prostate cancer cells still elusive. Therefore, the purpose of this study is to explore the antiproliferative and apoptotic effects of thymol against prostate cancer LNCaP cells. Our results indicated dosedependent growth inhibitory effects of thymol on prostate cancer LNCaP cells. Morphological analysis and DAPI staining revealed that thymol induces marked morphological and nuclear alterations in LNCaP cells. Moreover, thymol could induce significant apoptosis in LNCaP cells through caspase-3 activation and modulation of mRNA expression of apoptotic-related genes. Overall, these findings showed that thymol could offer a novel therapeutic approach against prostate cancer.
\end{abstract}

Keywords: thymol; prostate cancer; anticancer; apoptosis; caspase-3.

(C) 2021 by the authors. This article is an open-access article distributed under the terms and conditions of the Creative Commons Attribution (CC BY) license (https://creativecommons.org/licenses/by/4.0/).

\section{Introduction}

Prostate cancer is considered the most common form of malignancy in males. Various factors are considered the primary causes of increased cancer incidence rate, including race stress, age, and a high-fat diet [1]. However, Asian countries have lower incidences of cancers than Western countries due to their dietary habits, including tea, soy, fish, vegetables, and fruits $[2,3]$. However, adopting Western eating habits like the consumption of red meat and a highcalorie diet resulted in a rapid increase in cancer incidence in Asian countries. Effective therapeutic strategies with the least side effects and a multi-targeted approach are needed to relieve the increasing burden of cancer incidence worldwide.

Many research studies have reported that the uses of herbs, plants, and their bioactive compounds have been effective against several cancer cell lines in vitro and animal models via multiple pathways, ultimately leading to cell growth inhibition and cell death $[4,5]$. While there are high risks related to conventional therapies used for cancer treatment, therapies using natural compounds are suggested to have lower risks due to their specific targeting effect against cancer cells. Several plant-derived bioactive compounds such as catechins, curcumin, 
genistein, and rutin have anticancer activities [6, 7]. For example, various compounds like auriculacin, celastrol, and carvacrol have recently been shown to induce apoptosis and inhibit the growth of prostate cancer cells [8-10].

Thymol is a monoterpene phenol commonly found in the essential oils of numerous plants, like Thymus vulgaris and Carum copticum [11, 12]. Thymol has been reported to have several pharmacological activities, including antiseptic, antibacterial, anthelmintic, antifungal, antiviral, antioxidant, antispasmodic, anti-rheumatic, anticancer, anti-hyperglycemic, and antihyperlipidemic effects [13-15]. Recently, it has gained substantial attention due to its potential antitumor properties. Nevertheless, very less is known about the antitumor effects of thymol against prostate cancer. Thus, the present study was aimed to explore the antiproliferative and apoptotic effects of thymol against prostate cancer cells.

\section{Materials and Methods}

\subsection{Chemicals and reagents.}

Thymol and 4',6-diamidino-2-phenylindole (DAPI) staining dye were obtained from Sigma-Aldrich (St. Louis, MO, USA). MTT [3-(4,5-dimethylthiazol-2-yl)-2,5-diphenyl tetrazolium bromide], Fetal bovine serum, RPMI (Roswell Park Memorial Institute)-1640 media, and antibiotics were procured from Himedia India, Ltd. (Mumbai, India). Caspase-3 assay kit was purchased from BioVision U.S.A. cDNA synthesis kit (Product name: Verso), and qPCR Kit (DyNAmoColorFlash SYBR Green) were procured from Thermo Scientific, USA.

\subsection{Cell culture.}

The human prostate cancer LNCaP cell line and normal HaCaT cells were obtained from the National center for cell science, Pune (India) and maintained in RPMI medium with $10 \%$ fetal bovine serum and $1 \%$ antibiotic-antimycotic solution (Himedia, India).

\subsection{In vitro cell viability assay.}

MTT cell viability assay was carried out to examine the cytotoxic effect of thymol on prostate cancer LNCaP cells and normal HaCaT cells as described by Khan et al., 2020 [16]. Approximately $5 \times 10^{3}$ cells per well were seeded in 96-well plates and grown for $24 \mathrm{~h}$. After that, cells were exposed to various concentrations of thymol $(50,100,150,200$, and $250 \mu \mathrm{M})$. Thereafter, in each well $20 \mu \mathrm{L}$, MTT dye $\left(5 \mathrm{mg} / \mathrm{ml}\right.$ in PBS) was added for $3 \mathrm{~h}$ at $37^{\circ} \mathrm{C}$. Subsequently, formazan crystals were solubilized by DMSO (dimethyl sulfoxide) addition. The absorbance was then analyzed at $540 \mathrm{~nm}$ in a microplate reader to estimate percent cell viability (Bio-Rad, USA).

\subsection{Assessment of morphological changes.}

The growth inhibitory effect of thymol on prostate cancer LNCaP cells was evaluated by observing morphological changes in treated cells. Cells were seeded at a density of $5 \times 10^{3}$ cells/well in 96-well plates and allowed to grow for $24 \mathrm{~h}$. After incubation, cells were treated with various concentrations of thymol $(50,100,150,200$, and $250 \mu \mathrm{M})$ for $24 \mathrm{~h}$, and morphological alterations were observed by fluorescence microscope (Floid cell Imaging Station, Life Technologies, USA). 


\subsection{Apoptosis detection by DAPI staining.}

The effect of thymol on nuclear morphology related to apoptotic induction was evaluated by DAPI staining [17]. Thymol-treated LNCaP cells were washed twice with PBS, detached from the surface, and pellet down by centrifugation. Thereafter, cells were fixed with ice-cold methanol (10 min), and the cell membrane was permeabilized with Triton $\mathrm{X}-100$. Finally, DAPI dye was added to LNCaP cells for 10 minutes and examined under a fluorescence microscope (Floid cell Imaging Station, Life Technologies, USA).

\subsection{Estimation of caspase-3 activity.}

To monitor the effects of thymol on caspase-mediated apoptosis, caspase- 3 activity was assessed by Colorimetric Assay Kits (BioVision, USA). Briefly, cells (3x106) were lysed in cell lysis buffer (ice-cold) for 10 minutes, and then cell lysate was centrifuged to collect the supernatant. Further, $50 \mu \mathrm{l}$ lysate was transferred into a 96-well plate with $50 \mu \mathrm{l}$ of reaction buffer, comprising $10 \mathrm{mM}$ DTT. Afterward, $5 \mu \mathrm{l}$ of the $4 \mathrm{mM}$ substrate of each caspase was added in each well, incubated at $37^{\circ} \mathrm{C}$ for $1 \mathrm{~h}$, and absorbance recorded at $405 \mathrm{~nm}$ on a microtiter plate reader. Finally, percent caspase- 3 activity was calculated by comparing the data with the control sample.

\subsection{Analysis of caspase inhibitor effect on cell viability.}

To illustrate the growth inhibitory effects of thymol, LNCaP cells were pre-treated with $50 \mu \mathrm{M}$ of caspase- 3 inhibitor (Z-DEVD-FMK) for $2 \mathrm{~h}$. Subsequently, LNCaP cells were treated with various concentrations of thymol $(50,100,150,200$, and $250 \mu \mathrm{M})$ for $24 \mathrm{~h}$, and MTT cell viability assay was carried out to elucidate the role of caspase activation underlying the antiproliferative effect of thymol.

\subsection{Real-time qPCR analysis.}

The RNA extraction of treated and untreated cells was done using the HiPurATM Total RNA Miniprep Purification Kit (Himedia, India). The cDNA synthesis was carried out, and the mRNA expression level of target genes was estimated using SYBR Green qPCR Kit (Thermoscientific, USA). The primer sequences targets for this study were as following:

Bax;Forward: 5'-AAGAAGCTGAGCGAGTGT-3' Reverse: 5'GGAGGAAGTCCAATGTC-3', Bcl-2; Forward: 5'-TCCATGTCTTTGGACAACCA-3', Reverse: 5'-CTCCACCAGTGTTCCCATCT-3', and GAPDH; Forward: 5'GAAGGTCGGAGTCAACGGATTTGGT-3', Reverse Primer: 5'CATGTGGGCCATGAGGTCCACCAC-3'. GAPDH (Glyceraldehyde-3-phosphate dehydrogenase) gene was used as an internal control and the data evaluated by the comparative $2-\Delta \Delta \mathrm{Ct}$ threshold cycle.

\subsection{Statistical analysis.}

Experimental data from three independent experiments, performed in triplicate, and represented as the mean \pm S.E.M. Statistical analysis was done using one-way ANOVA coupled with Dunnett's post hoc test for multiple comparisons with control (*p<0.01, **p $<0.001$ represent significant difference compared with control). 


\section{Results and Discussion}

\subsection{Results.}

\subsubsection{Thymol inhibited cell growth in LNCaP cells}

Human prostate cancer LNCaP cells were treated with/without varying concentrations of thymol for $24 \mathrm{~h}$, and then cell viability was estimated by MTT assay. Thymol treatment resulted in a significant reduction in the growth of human prostate cancer LNCaP cells in a dose-responsive manner. Results shown that after $24 \mathrm{~h}$ of thymol $(50,100,150,200$, and 250 $\mu \mathrm{M})$ treatment, cell viability of LNCaP cells reduced by $94.38 \%, 75.86 \%, 64.48 \%, 44.2 \%$, $32.61 \%$ and $20.58 \%$, respectively (Figure 1A). However, insignificant cytotoxic effects of thymol were observed on normal HaCaT cells were found as compared to prostate cancer cells (Figure 1B).

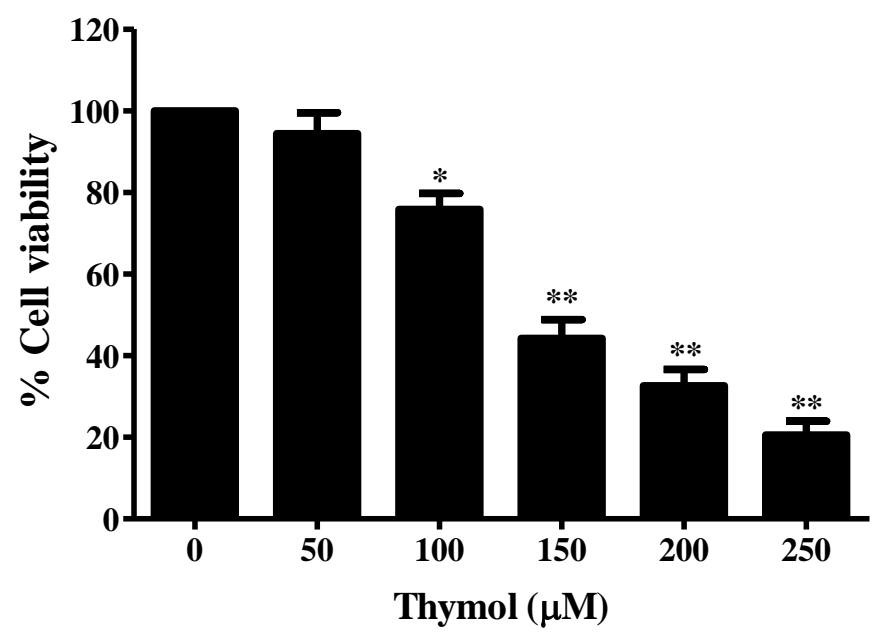

(A)

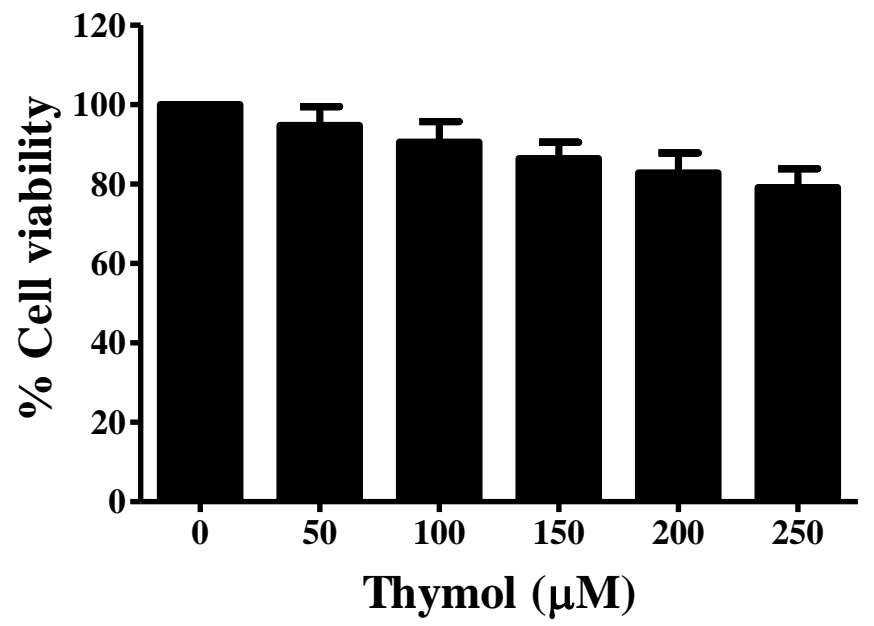

(B)

Figure 1. Cytotoxic effect of thymol on normal HaCaT cells and human prostate cancer LNCaP cell line assessed by MTT assay (A) Percent cell viability of normal HaCaT cells exposed to various concentrations of thymol (50-250 $\mu \mathrm{M}$ ) for 24; (B) Percent cell viability of LNCaP cells exposed to various concentrations of thymol $(50-250 \mu \mathrm{M})$ for 24 . Results were represented by mean \pm SEM and significant differences were compared to the control $(* \mathrm{p}<0.01$ and $* \mathrm{p}<0.001)$. 


\subsubsection{Thymol-induced morphological changes in $\mathrm{LNCaP}$ cells.}

To investigate the visible effects of thymol on LNCaP cells, phase-contrast microscopic analysis was performed. As clearly evident from the figure, exposure of thymol $(50-250 \mu \mathrm{M})$ on LNCaP prostate cancer cells exhibited significant morphological alterations in a dosedependent manner compared to control. The morphological changes involve cell shrinkage and a decrease in cell count, which was more pronounced with increasing concentrations (Figure $2 \mathrm{~A})$.

\subsubsection{Thymol-induced nuclear condensation in LNCaP cells.}

Analysis of preliminary events of apoptotic induction in thymol treated cells, DAPI staining was done. After treatment with thymol $(100,150$, and $200 \mu \mathrm{M})$ for $24 \mathrm{~h}$, marked nuclear changes were observed in LNCaP cells. Results of fluorescence micrographs clearly suggested that thymol induced nuclear condensation and fragmentation in a dose-dependent manner, while normal cells displayed normal cell morphology (Figure 2B).

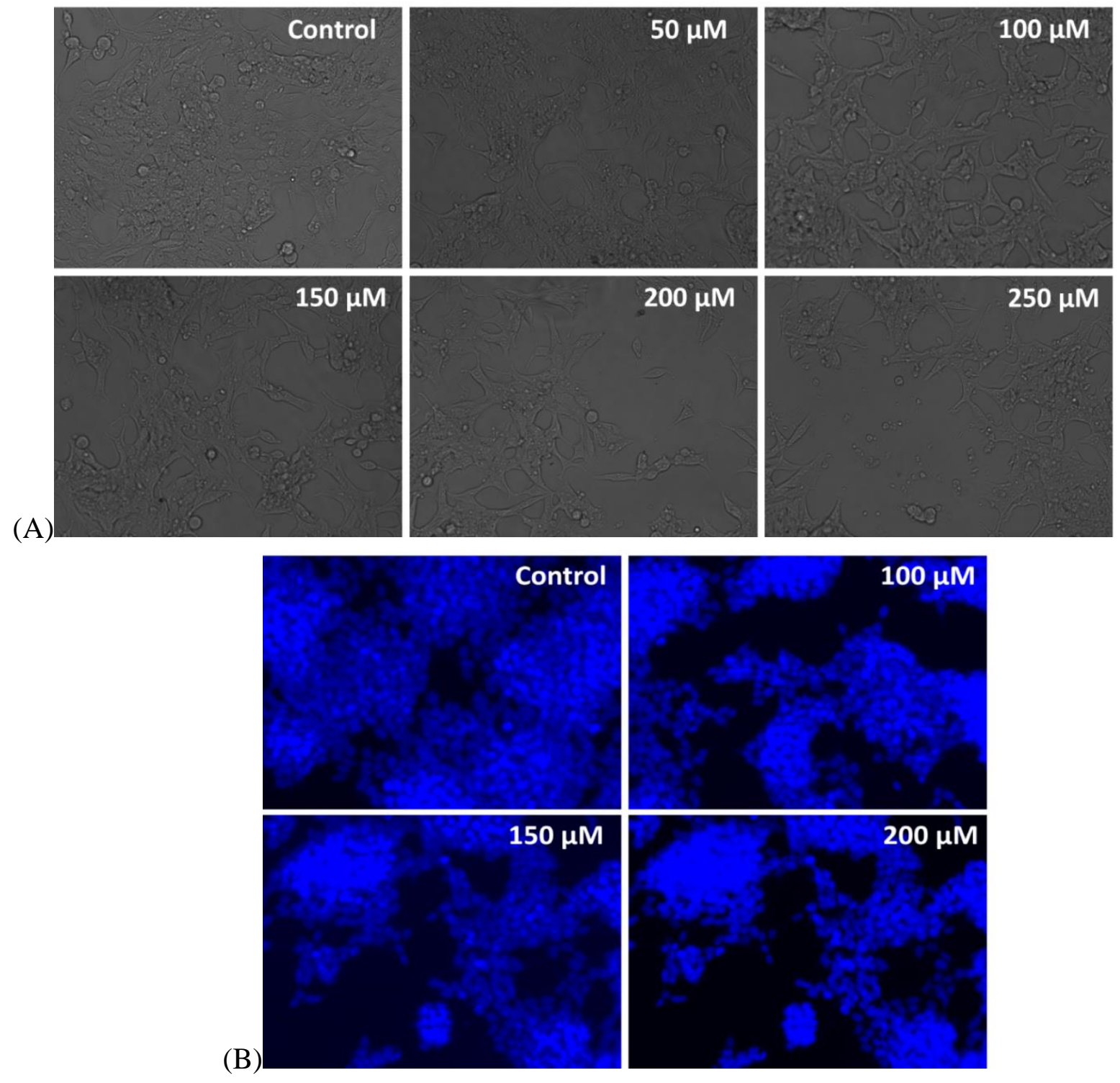

Figure 2. (A) Phase-contrast photomicrograph of LNCaP cells exposed with various doses of thymol (50-250 $\mu \mathrm{M}$ ) for $24 \mathrm{~h}$; (B) Thymol induced nuclear morphological changes as evaluated by DAPI-stained nuclei of LNCaP cells treated with different concentrations of thymol $(100,150,200 \mu \mathrm{M})$ for $24 \mathrm{~h}$. 
3.1.4. Thymol induced caspase-3 activity in LNCaP cells.

To understand the role of caspase activation in apoptosis induction, we determined caspase- 3 activity in the treated and untreated control. Results revealed significant caspase- 3 activation in LNCaP cells after treatment with various concentrations of thymol for $24 \mathrm{~h}$ (Figure 3A). Caspase-3 activity was markedly increased as compared to control by $52.03 \%$, $88.87 \%$, and $136.79 \%$ at a concentration of 100,150 , and $200 \mu \mathrm{M}$ of thymol, respectively.

Additionally, to further confirm whether caspase activation played a role in thymolinduced cytotoxicity in LNCaP cells, a cell viability assay was performed after pre-treatment with a caspase inhibitor. The results suggested that caspase inhibitor pre-treatment resulted in significant attenuation in the thymol-induced cytotoxicity in prostate cancer LNCaP cells (Figure 3B).

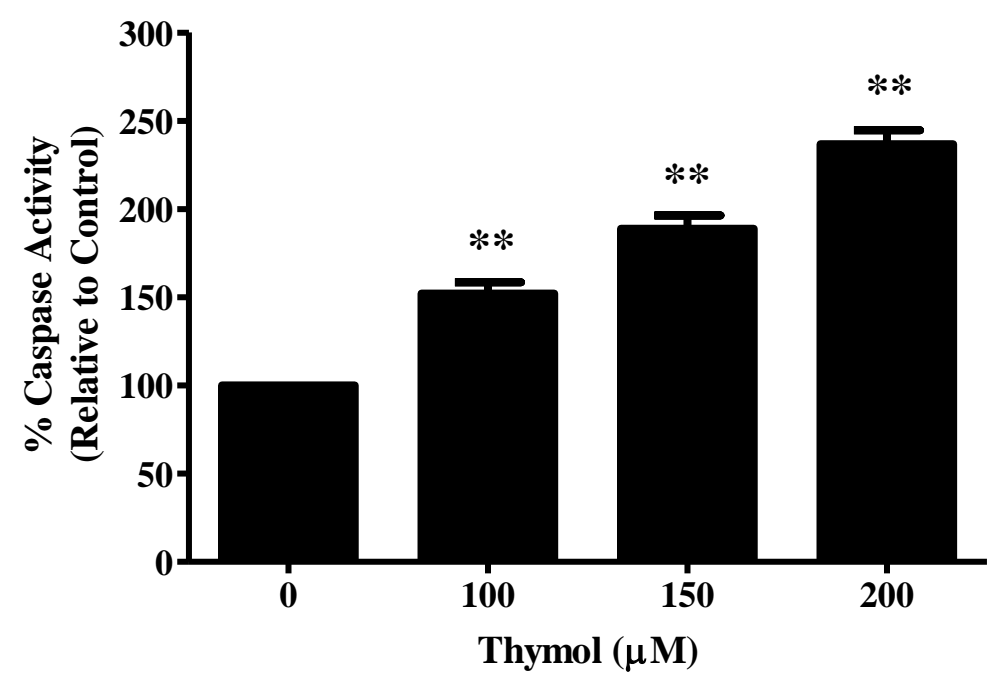

(A)

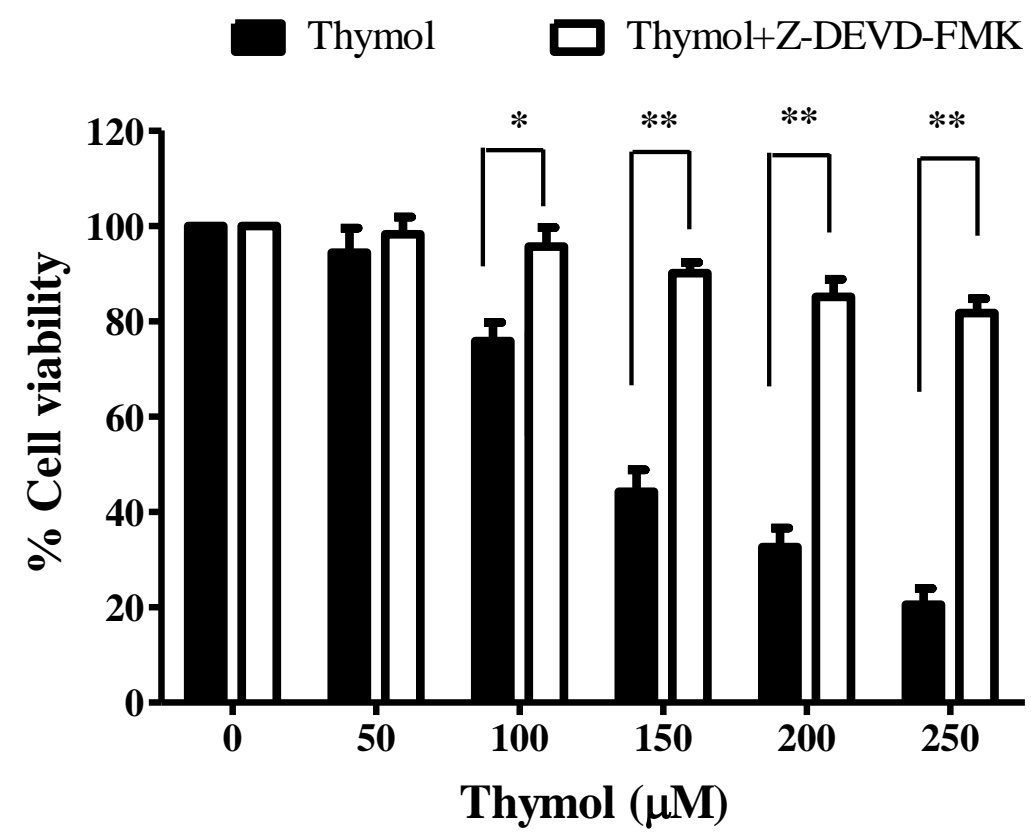

(B)

Figure 3. Dose-dependent apoptosis induction via caspase-3 activation in thymol-treated LNCaP cells (A) Percent caspase-3 activation in LNCaP cells exposed with various concentrations of thymol (100, 150, and 250 $\mu \mathrm{M}$ ) for $24 \mathrm{~h}$; (B) Percent cell viability of LNCaP cells pre-treated with Z-DEVD-FMK (caspase-3 inhibitor) and then exposed with various doses of thymol $(0-250 \mu \mathrm{M})$ for $24 \mathrm{~h}$ evaluated by MTT assay. Results were represented by mean \pm SEM, and significant differences were compared to the control $(* \mathrm{p}<0.01$ and $* \mathrm{p}<0.001)$. 
3.1.5. Thymol modulates mRNA expression of apoptosis-associated genes.

To explore the antiproliferative mechanism associated with apoptotic induction in the thymol-treated LNCaP cells, RT-qPCR evaluated the mRNA expression of Bcl-2 family proteins. Results demonstrated that thymol treatment significantly elevated Bax mRNA expression level in prostate cancer LNCaP cells (Figure 4A). Moreover, the mRNA expression of the anti-apoptotic Bcl-2 gene was decreased in a concentration-dependent manner after thymol treatment (Figure 4B).

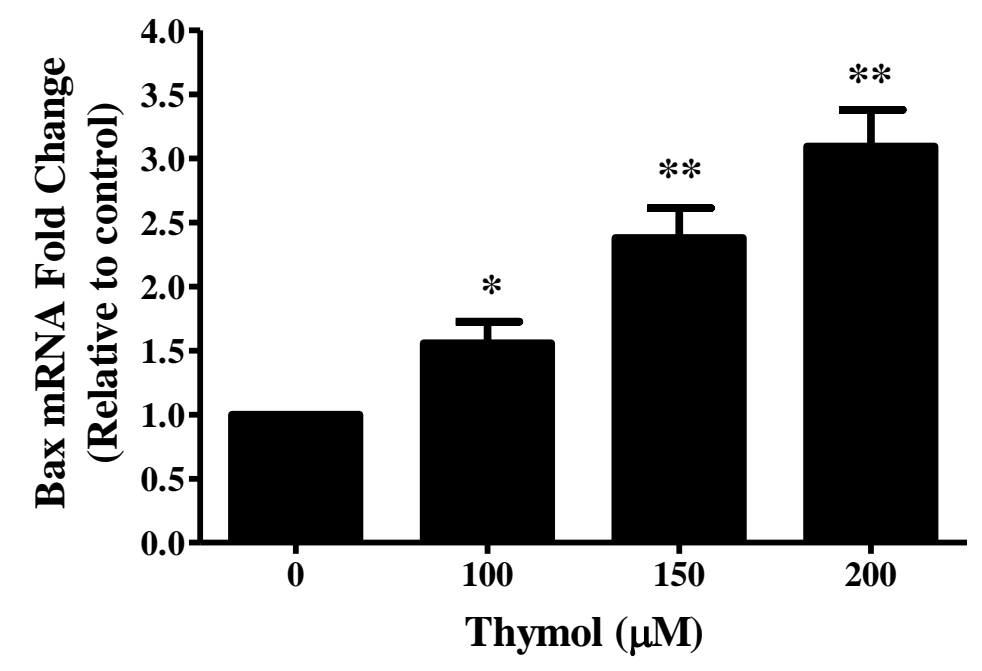

(A)

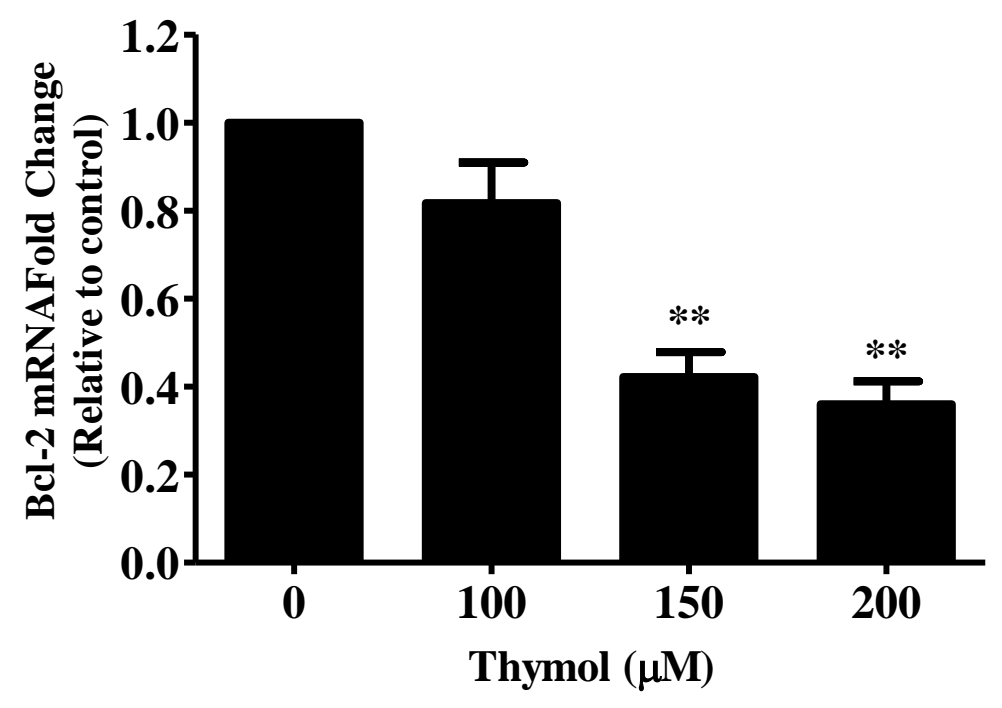

(B)

Figure 4. Effect of thymol on modulation of apoptotic related Bcl-2 mRNA expression in human prostate cancer LNCaP cells. (A) Upregulated mRNA expression of pro-apoptotic Bax gene; (B) Downregulated mRNA expression of anti-apoptotic Bcl-2 gene in thymol-treated LNCaP cells examined by quantitative real-time PCR. Results were represented by mean \pm SEM, and significant differences were compared to the control $(* \mathrm{p}<0.01$ and $* \mathrm{p}<0.001)$.

\subsection{Discussion.}

Natural phytocompounds have already gained increasing consideration in cancer therapeutics due to their biologically responsive nature and low toxicity in normal cells [1821]. One of such phenolic monoterpene is thymol which is mostly found in thyme species plants. It is one of the major constituents of thyme essential oil [23]. Essential oil containing thymol has long been used in folk medicine as antiviral, expectorant, antiseptic agents, 
antibacterial, anti-inflammatory, and the management of the upper respiratory system [24-28]. The current research focused on thyme essential oil and thyme for finding novel biologicals or therapeutic compounds as natural plant substances. However, few studies are still reported that evaluate thymol's anticancer potential against various types of cancer. Based on these shreds of evidence, we demonstrated the growth inhibitory and apoptotic inducing effects of thymol in prostate cancer LNCaP cells. As shown in Figure 1A, thymol treatment can inhibit prostate cancer cell growth, while insignificant cytotoxicity was seen in normal HaCaT cells, as detected by the MTT cell viability assay (Figure 1A and B). Moreover, the morphological analysis demonstrated the cell membrane disruption and cell shrinkage of prostate cancer cells after thymol treatment (Figure 2A). These results are in accordance with the data published by other researchers [29-31].

Apoptosis is a crucial event characterized by the cells' distinct cellular and morphological variations, including cellular detachment, shrinkage, nuclear fragmentation, and apoptotic body formation [32]. Our results were also per the above notion where condensed and fragmented nuclei were observed in LNCaP cells, suggesting that thymol induced apoptosis in prostate cancer cells (Figure 2B) [33].

Caspase- 3 is considered one of the main apoptosis execution components, which is directly involved in the proteolytic cleavage of many target cellular proteins [34]. Thus, we examined caspase- 3 activity in treated and untreated cells, and results showed that thymol treatment-induced caspase-3 activation, which further leads to apoptotic cell death (Figure 3A). While pre-treatment with caspase-3 inhibitor (Z-DEVD-FMK) markedly attenuates thymolinduced cytotoxicity in prostate cancer LNCaP cells, confirms caspase-3 activation during thymol-induced apoptosis (Figure 3B).

Several studies suggested the regulatory involvement of Bcl-2 family proteins during apoptotic induction $[35,36]$. To gain insight into the molecular mechanism related to apoptosis induction by thymol, mRNA expression of the key apoptotic genes Bcl-2 and Bax was analyzed in $\mathrm{LNCaP}$ cells. The results clearly demonstrated that thymol upregulates Bax mRNA expression and downregulates Bcl-2 mRNA expression in a dose-dependent manner suggesting the association of Bcl-2 family proteins with apoptotic induction stimulated by thymol in LNCaP prostate cancer cells (Figure 4A and B).

\section{Conclusions}

Overall, it may be proposed that thymol has significant anticancer and apoptotic potential against prostate cancer LNCaP cells. Based on the above results and findings, we could suggest that thymol-mediated cell growth inhibition is related to caspase-mediated apoptotic induction in prostate cancer cells. To the best part of my knowledge, this study is the first to illustrate the growth inhibitory and apoptotic inducing effects of thymol in human prostate cancer LNCaP cells. More studies are still needed, including in vivo animal and clinical studies, to verify further whether thymol treatment is effective against prostate cancer and could be used as a chemotherapeutic agent against prostate cancer.

\section{Funding}

This research received no external funding. 


\section{Acknowledgments}

The authors thank the Noida Institute of Engineering \& Technology Management, Greater Noida, for providing the facilities to carry out this study.

\section{Conflicts of Interest}

The authors declare no conflict of interest.

\section{References}

1. Kimura, T.; Egawa, S. Epidemiology of prostate cancer in Asian countries. Int J Urol. 2018, 25, 524-531, https://doi.org/10.1111/iju.13593.

2. Barsouk, A.; Padala, S.A.; Vakiti, A.; Mohammed, A.; Saginala, K.; Thandra, K.C.; Rawla, P.; Barsouk, A. Epidemiology, Staging and Management of Prostate Cancer. Med Sci (Basel). 2020, 8, 28. https://doi.org/10.3390/medsci8030028.

3. Culp, M.B.; Soerjomataram, I.; Efstathiou, J.A.; Bray, F.; Jemal, A. Recent global patterns in prostate cancer incidence and mortality rates. Eur Urol. 2020, 77, 38-52, https://doi.org/10.1016/j.eururo.2019.08.005.

4. Khan, T.; Ali, M.; Khan, A.; Nisar, P.; Jan, S.A.; Afridi, S.; Shinwari, Z.K. Anticancer plants: A review of the active phytochemicals, applications in animal models, and regulatory aspects. Biomolecules 2020, 10, 47. https://doi.org/10.3390/biom10010047.

5. Li, X.; He, T.; Wang, X.; Shen, M.; Yan, X.; Fan, S.; Wang L; Wang X; Xu X; Sui H; She, G. Chemical Constituents and Biological Activities of Plants from the Genus Thymus. Chem Biodivers. 2019, 16, e1900254. https://doi.org/10.1002/cbdv.201900254.

6. Lambert, J.D.; Hong, J.; Yang, G.Y.; Liao, J.; Yang, C.S. Inhibition of carcinogenesis by polyphenols: evidence from laboratory investigations. Am $J$ Clin Nutr 2005, 81, 284S-291S, https://doi.org/10.1093/ajcn/81.1.284S.

7. Dehelean, C.A.; Marcovici, I.; Soica, C.; Mioc, M.; Coricovac, D.; Iurciuc, S.; Cretu, O.M.; Pinzaru, I. PlantDerived Anticancer Compounds as New Perspectives in Drug Discovery and Alternative Therapy. Molecules 2021, 26, 1109, https://doi.org/10.3390/molecules26041109.

8. Won, Y.S; Seo, K.I. Sanggenol L induces apoptosis and cell cycle arrest via activation of p53 and suppression of PI3K/Akt/mTOR signaling in human prostate cancer cells. Nutrients 2020, 12, 488, https://doi.org/10.3390/nu12020488.

9. Khan, F., Khan, I., Farooqui, A. and Ansari, I.A., Carvacrol induces reactive oxygen species (ROS)-mediated apoptosis along with cell cycle arrest at G0/G1 in human prostate cancer cells. Nutr Cancer. 2017, 69, 10751087, https://doi.org/10.1080/01635581.2017.1359321.

10. Khan, F.; Singh, V.K.; Saeed, M.; Kausar, M.A.; Ansari, I.A. Carvacrol induced program cell death and cell cycle arrest in androgen-independent human prostate cancer cells via inhibition of notch signaling. Anticancer Agents Med Chem. 2019, 19, 1588-1608, https://doi.org/10.2174/1871520619666190731152942.

11. Salehi, B.; Mishra, A.P.; Shukla, I.; Sharifi-Rad, M.; Contreras, M.D.M.; Segura-Carretero, A.; Fathi, H.; Nasrabadi, N.N.; Kobarfard, F.; Sharifi-Rad, J. Thymol, thyme, and other plant sources: Health and potential uses. Phytother Res. 2018, 32, 1688-1706, https://doi.org/10.1002/ptr.6109.

12. Nagoor Meeran, M.F.; Javed, H.; Al Taee, H.; Azimullah, S.; Ojha, S.K. Pharmacological properties and molecular mechanisms of thymol: prospects for its therapeutic potential and pharmaceutical development. Front Pharmacol. 2017, 8, 380, https://doi.org/10.3389/fphar.2017.00380.

13. Islam, M.T.; Khalipha, A.B.; Bagchi, R.; Mondal, M.; Smrity, S.Z.; Uddin, S.J.; Shilpi, J.A.; Rouf, R. Anticancer activity of thymol: A literature-based review and docking study with Emphasis on its anticancer mechanisms. IUBMB Life 2019, 71, 9-19. https://doi.org/10.1002/iub.1935.

14. Araniti, F.; Miras-Moreno, B.; Lucini, L.; Landi, M.; Abenavoli, M.R. Metabolomic, proteomic and physiological insights into the potential mode of action of thymol, a phytotoxic natural monoterpenoid phenol. Plant Physiol Biochem. 2020, 153, 141-153, https://doi.org/10.1016/j.plaphy.2020.05.008.

15. Aydın, E.; Turkez, H.; Tasdemir, S.; Hacimuftuoglu, F. Anticancer, antioxidant and cytotoxic potential of thymol in vitro brain tumor cell model. Cent Nerv Syst Agents Med Chem. 2017, 17, 116-122, https://doi.org/10.2174/1871524916666160823121854. 
16. Khan, F.; Pandey, P.; Mishra, R.; Arif, M.; Kumar, A.; Jafri, A.; Mazumder, R. Elucidation of S-Allylcysteine Role in Inducing Apoptosis by Inhibiting PD-L1 Expression in Human Lung Cancer Cells. Anticancer Agents Med Chem. 2021, 21, 532-541, https://doi.org/10.2174/1871520620666200728121929.

17. Khan, F.; Pandey, P.; Ahmad, V.; Upadhyay, T.K. Moringa oleifera methanolic leaves extract induces apoptosis and G0/G1 cell cycle arrest via downregulation of Hedgehog Signaling Pathway in human prostate PC-3 cancer cells. J Food Biochem. 2020, 44, e13338, https://doi.org/10.1111/jfbc.13338.

18. Newman, D.J.; Cragg, G.M. Natural products as sources of new drugs over the nearly four decades from 01/1981 to 09/2019. J Nat Prod. 2020, 83, 770-803, https://doi.org/10.1021/acs.jnatprod.9b01285.

19. Newman, D.J.; Cragg, G.M. Natural products as sources of new drugs over the last 25 years. J Nat Prod. 2007, 70, 461-477. https://doi.org/10.1021/np068054v.

20. Ganesan, A.; Arimondo, P. B.; Rots, M. G.; Jeronimo, C.; Berdasco, M. (2019). The timeline of epigenetic drug discovery: from reality to dreams. Clin Epigenetics. 2019, 11, 174. https://doi.org/10.1186/s13148-0190776-0.

21. Atanasov, A.G.; Zotchev, S.B.; Dirsch, V.M.; Supuran, C.T. Natural products in drug discovery: advances and opportunities. Nat Rev Drug Discov. 2021, 1-17, https://doi.org/10.1038/s41573-020-00114-z.

22. Rayan, A.; Raiyn, J.; Falah, M. Nature is the best source of anticancer drugs: Indexing natural products for their anticancer bioactivity. PloS one 2017, 12, 0187925, https://doi.org/10.1371/journal.pone.0187925.

23. Salehi, B.; Mishra, A.P.; Shukla, I.; Sharifi-Rad, M.; Contreras, M.D.M.; Segura-Carretero, A.; Fathi, H.; Nasrabadi, N.N.; Kobarfard, F.; Sharifi-Rad, J. Thymol, thyme, and other plant sources: Health and potential uses. Phytother Res. 2018, 32, 1688-1706, https://doi.org/10.1002/ptr.6109.

24. Salama, M.; El-Ahwany, A.M.; Elkenany, E.T.; Abdeldaim, A.A. An in vitro study on antimicrobial and anticancer potentiality of thyme and clove oils. Rend. Fis. Acc. Lincei. 2018, 29, 131-139, https://doi.org/10.1007/s12210-018-0672-0.

25. Kowalczyk, A.; Przychodna, M.; Sopata, S.; Bodalska, A.; Fecka, I. Thymol and Thyme Essential Oil-New Insights into Selected Therapeutic Applications. Molecules. 2020, 25, 4125, https://doi.org/10.3390/molecules25184125.

26. de Oliveira, J.R.; Figueira, L.W.; Sper, F.L.; Meccatti, V.M.; Camargo, S.E.A.; de Oliveira, L.D. Thymus vulgaris L. and thymol assist murine macrophages (RAW 264.7) in the control of in vitro infections by Staphylococcus aureus, Pseudomonas aeruginosa, and Candida albicans. Immunol Res. 2017, 65, 932-943, https://doi.org/10.1007/s12026-017-8933-z.

27. Sheorain, J.; Mehra, M.; Thakur, R.; Grewal, S.; Kumari, S. In vitro anti-inflammatory and antioxidant potential of thymol loaded bipolymeric (tragacanth gum/chitosan) nanocarrier. Int J Biol Macromol. 2019, 125, 1069-1074, https://doi.org/10.1016/j.ijbiomac.2018.12.095.

28. Nabissi, M.; Marinelli, O.; Morelli, M.B.; Nicotra, G.; Iannarelli, R.; Amantini, C.; Santoni, G.; Maggi, F. Thyme extract increases mucociliary-beating frequency in primary cell lines from chronic obstructive pulmonary disease patients. Biomed Pharmacother. 2018, 105, 1248-1253, https://doi.org/10.1016/j.biopha.2018.06.004.

29. Jamali, T.; Kavoosi, G.; Safavi, M.; Ardestani, S.K. In-vitro evaluation of apoptotic effect of OEO and thymol in 2D and 3D cell cultures and the study of their interaction mode with DNA. Sci rep. 2018, 8, 1-19, https://doi.org/10.1038/s41598-018-34055-w.

30. Kang, S.H.; Kim, Y.S.; Kim, E.K.; Hwang, J.W.; Jeong, J.H.; Dong, X.; Lee, J.W.; Moon, S.H.; Jeon, B.T.; Park, P.J. Anticancer effect of thymol on AGS human gastric carcinoma cells. J Microbiol Biotechnol 2016, 26, 28-37, https://doi.org/10.4014/jmb.1506.06073.

31. Elbe, H.; Yigitturk, G.; Cavusoglu, T.; Uyanikgil, Y.; Ozturk, F. Apoptotic effects of thymol, a novel monoterpene phenol, on different types of cancer. Bratisl Lek Listy 2020, 121, 122-128. https://doi.org/10.4149/BLL_2020_016.

32. Abate, M.; Festa, A.; Falco, M.; Lombardi, A.; Luce, A.; Grimaldi, A.; Zappavigna, S; Sperlongan, P; Irace, C; Caraglia, M; Misso, G. Mitochondria as playmakers of apoptosis, autophagy and senescence. Semin Cell Dev Biol. 2020, 98, 139-153. https://doi.org/10.1016/j.semcdb.2019.05.022.

33. Chauhan, A.K.; Bahuguna, A.; Paul, S.; Kang, S.C. Thymol elicits HCT-116 colorectal carcinoma cell death through induction of oxidative stress. Anti-Cancer Agents Med. Chem 2017, 17, 1942-1950, https://doi.org/10.2174/1871520617666170327121228.

34. Boice, A; Bouchier-Hayes, L. Targeting apoptotic caspases in cancer. Biochim Biophys Acta Mol Cell Res. 2020, 1867, 118688. https://doi.org/10.1016/j.bbamcr.2020.118688. 
35. Zhang, X; Liu, X; Zhou, D; Zheng, G. Targeting anti-apoptotic BCL-2 family proteins for cancer treatment. Future Med Chem. 2020, 12, 563-565. https://doi.org/10.4155/fmc-2020-0004.

36. Li, J.; Liu, F.; Jiang, S.; Liu, J.; Chen, X.; Zhang, S.; Zhao, H. Berberine hydrochloride inhibits cell proliferation and promotes apoptosis of non-small cell lung cancer via the suppression of the MMP2 and Bcl2/Bax signaling pathways. Oncol Lett 2018, 15, 7409-7414, https://doi.org/10.3892/ol.2018.8249. 